\title{
A investigação sobre ética e política na dinâmica da pesquisa em educação no Brasil e sua importância para a formação do educador ${ }^{1}$
}

Dermeval Saviani

Professor Emérito da UNICAMP

Coordenador Geral do HISTEDBR

\section{Resumo}

O texto resgata os fundamentos históricos e conceituais de Ética na tradição cultural ocidental. Define os pressupostos políticos da Ética e indica a proeminência do ponto de partida teórico-metodológico, consubstanciando os elementos que sinalizam a direção em que se movem os conteúdos da ética e da política. Faz um inventário crítico das principais teorias éticas e políticas e destaca as fontes a serem analisadas nesse campo investigativo da Filosofia e da Educação. Articula os projetos históricos de integração entre Ética e Política com a Educação. Define que o campo da Filosofia da Educação apresenta-se como espaço de exploração das questões éticas e políticas que repercutem na educação enquanto atividade que se inscreve na esfera pública, sujeita, portanto, ao poder de Estado, com a incumbência de formar indivíduos moralmente aptos para agir no ambiente societário. Apresenta os pressupostos de concepção da educação como formação do homem que, como tal, exige a reflexão sobre os fundamentos éticos de seu agir moral e político. A educação assume o caráter de uma atividade mediadora no seio da prática social inserindo-se, portanto, no coração da ética e da política. Destaca a necessidade de formar o educador para que reúna condições de enfrentar os desafios morais, éticos e políticos que sobrevêm ao próprio processo de formação. Os desafios morais e éticos se manifestam de forma particularizada nas condições que vigoram hoje em nossa sociedade. Cabe ao pesquisador buscar desvendar suas fundamentações e alcances.

Palavras-chave: Ética; Política; Educador; Formação; Filosofia da Educação.

\footnotetext{
${ }^{1}$ Conferência de abertura do I Simpósio Nacional sobre Política, Ética e Educação (I POIETHOS). Campinas, 11 de junho de 2008.
} 


\section{1. Ética: a força da palavra}

$\checkmark \int \begin{aligned} & \text { o princípio era o verbo". Essa frase que abre o } \\ & \text { Evangelho de S. João se complementa, no final, com a } \\ & \text { prescrição de Jesus: “Assim como o Pai me enviou a }\end{aligned}$ mim, também eu vos envio a vós”. Envia para quê? A resposta aparece de forma mais clara nas passagens finais do Evangelho de S. Mateus: "Ide e ensinai a todas as gentes”, assim como nos versículos conclusivos de S. Marcos: "Ide por todo o mundo, pregai o Evangelho a toda a criatura".

O cumprimento pelos discípulos dessa prescrição de Cristo resultou na difusão da ética cristã que, incorporando as contribuições dos clássicos gregos e latinos, tornou-se a referência dominante para a moral no Ocidente.

Essa tradição da pregação cristã que remonta aos apóstolos, tendo a destacada participação de São Paulo, foi posta em cheque no século XVI pela Reforma Protestante encabeçada por Lutero, com a tese da "sola scriptura” que declarava ser suficiente o conhecimento das escrituras para alimentar a graça da fé em Cristo. Mas essa tese provocou a reação da contra-reforma que foi buscar na Retórica a fundamentação para o revigoramento da tradição oral, dando origem ao período barroco.

Resgatando a oratória e retórica dos gregos e romanos, com destaque para Aristóteles, Cícero e Quintiliano, o período barroco produziu uma força persuasiva difusora da ética cristã nas várias esferas culturais sobressaindose a música e literatura que, na verdade, se fundiam, de modo especial quando a música se expressava na forma do canto, fosse ele solo ou coral. Da mesma forma que os oradores, os músicos (compositores e intérpretes) alimentavam a ambição de provocar, movimentar e regular os afetos ou paixões dos ouvintes. E essa ambição tinha um claro sentido ético, pois se acreditava a serviço da verdade e da justiça. Tanto a oratória que se expressava principalmente nos sermões, como a literatura seja em prosa ou em verso, assim como a música eram atravessadas pela retórica barroca expressando-se em frases orais, escritas ou melódicas, cujas regras de 
construção implicavam os cinco passos seguintes, baseados na retórica clássica de Aristóteles, Cícero e Quintiliano: inventio (criação dos argumentos), dispositio (ordenação e distribuição dos argumentos), elocutio (composição do texto escrito ou da peça musical), memória (refere-se aos mecanismos para memorizar o discurso. Observe-se, porém, que esse passo retórico ficou restrito à literatura, não se transmitindo para as outras artes) e pronunciatio (execução do discurso, assumindo a forma oral nos sermões, a redação e leitura na literatura e a interpretação instrumental e/ou vocal na música). Anote-se que a dispositio, por sua vez, se desdobrava em vários momentos, assim definidos por Cano (2000, p. 71-115): exordium (introdução), narratio (apresentação dos fatos), propositio (enunciação da tese principal), confutatio (defesa argumentada da tese), confirmatio (retomada da tese principal, agora na forma de um enunciado demonstrado) e peroratio (conclusão ou epílogo em que a tese é enfatizada).

Esse entrelaçamento entre a literatura e a música propiciado pela retórica do período barroco é ilustrado magistralmente na suíte "Dom Quixote”, de Georg Philipp Telemann, compositor alemão que viveu entre 1681 e 1767. Por meio da saga de D. Quixote com seu fiel escudeiro Sancho Pança, Cervantes (1547-1616) combate, pela ironia, o modo de vida que prevalecera na Idade Média e que ainda seduzia uma aristocracia já vencida pelas novas condições sociais representadas pela ascensão da burguesia, cuja vitória viria a se expressar politicamente na Revolução Francesa e economicamente na Revolução Industrial. A suíte composta por Telemann é o resultado da transposição para a música de sua leitura da obra de Cervantes. A peça, com a duração de 16 minutos e 68 segundos, se desdobra em sete movimentos (abertura; o despertar de Quixote; seu ataque aos moinhos de vento; os suspiros amorosos pela princesa Dulcinéia; Sancho Pança faz troça; o galope de Rocinante / e o do asno de Sancho; o leito de Dom Quixote).

A vida cavalheiresca, objeto da crítica ácida de Miguel de Cervantes, se caracteriza por uma ética pautada pelos valores da fidalguia, vale dizer, generosidade, nobreza, liberalidade; pela fidelidade, honradez, bravura e 
ambição de glória, valores esses que se procurava traduzir no preparo militar, nas atividades desportivas com destaque para a caça, em comportamentos morais afáveis, em boas maneiras no trajar, no falar e no comer, na proteção das mulheres, dos órfãos, viúvas e anciãos. Essas virtudes e ideais cavalheirescos eram difundidos e exaltados pelos livros de cavalaria.

É interessante observar que no primeiro livro "O engenhoso fidalgo Dom Quixote de la Mancha”, publicado em 1605, Dom Quixote morre como o “perfeito cavalheiro”, quer dizer, na ironia de Cervantes, um perfeito bufão, sendo sepultado “com diferentes epitáfios e elogios de sua vida e costumes” (CERVANTES, 2004, p. 529). Já o segundo livro, publicado em 1615, se encerra com D. Quixote abjurando o ideal cavalheiresco e lavrando seu testamento no qual, na parte relativa à sua sobrinha, sentencia: “se Antonia Quijana minha sobrinha quiser casar-se, se case com homem de quem primeiro se tenha informado que não sabe que coisas sejam livros de cavalaria; e no caso de se averiguar que o sabe e, apesar disso, minha sobrinha quiser casar-se com ele e, de fato venha a se casar, perca tudo o que lhe mandei, podendo meus testamenteiros distribuir tudo o que lhe cabia em obras pias à sua vontade” (idem, ibidem, p. 1.103). E num de seus vários epitáfios, podemos ler:

Teve a todo o mundo em pouco,

foi o espantalho e ogro

do mundo, em tal conjuntura,

que acreditou sua ventura

morrer lúcido e viver louco.

Da leitura desse epitáfio parece lícito concluir que a mensagem a nós deixada por Cervantes é que a suprema lucidez do perfeito cavalheiro se encontra na morte. Ou seja: a vida cavalheiresca é pura loucura e o advento da razão coincide com o desaparecimento dos ideais da fidalguia. Assim, a obra de Cervantes já prenunciava no início do século XVII a chegada do 
iluminismo que virá a se impor na segunda metade do século XVIII. E com a vinda das luzes o classicismo tomará o lugar do barroco: a Monteverdi (1567-1643), Buxtehude (1637-1707), Corelli (1653-1713), Vivaldi (16781741), Telemann (1681-1767), J.S.Bach (1685-1750) e Haendel (16851759) sucedem Haydn (1732-1809), Mozart (1756-1791) e Beethoven (1770-1827). E a ética ganhará sua grande sistematização formal com a elaboração de Kant (1724-1804).

\section{2. Ética, política e pedagogia: o substrato comum das ciências da ação}

“No princípio era a ação”. Com essa frase de Fausto, Goethe contrapõe-se ao que vê escrito no Evangelho de João ("no princípio era o verbo”). Ao abrir o livro do Novo Testamento, Fausto proclama:

Escrito está: "Era no início o Verbo!”

Começo apenas, e já me exacerbo!

Como hei de ao verbo dar tão alto apreço?

De outra interpretação careço;

Se o espírito me deixa esclarecido,

Escrito está: No início era o Sentido!

Pesa a linha inicial com calma plena,

Não se apressure a tua pena!

É o sentido então, que tudo opera e cria?

Deverá opor! No início era a Energia!

Mas, já, enquanto assim o retifico,

Diz-me algo que tampouco nisso fico.

Do espírito me vale a direção,

E escrevo em paz: Era no início a Ação! (GOETHE, 1987, p. 68). 
Contra a "Civilização pela palavra” (HANSEN, 2000, p. 19-41) afirma-se agora a “civilização pela ação”. Se Cervantes prenuncia o racionalismo em sua crítica á cavalaria, Goethe, com o movimento alemão “Sturm und drang” (tempestade e paixão) abre a era do romantismo. Na música Beethoven (1770-1827) faz a transição dos clássicos para o romantismo que terá como representantes Mendelssohn (1809-1847), Chopin (1810-1849), Liszt (1811-1886), Brahms (1833-1897), Tchaikovsky (1840-1893) e o norueguês Grieg (1843-1907).

A partir da perspectiva do romantismo, Goethe irá fazer coro com Hegel na crítica dialética ao iluminismo. A crítica de Hegel foi formulada na Fenomenologia do espírito (1807) no capítulo denominado “A ilustração” (HEGEL, 1973, pp.317-343). Em sua crítica Hegel sublinha o fato de que o iluminismo se resume a uma visão formal, carecendo de conteúdo objetivo, isto é, o conhecimento do devir histórico: “a pura intelecção não pode ter aqui nenhuma atividade e nenhum conteúdo próprios” (idem, p. 318). Na mesma linha vai a crítica de Goethe em Fausto, publicado em 1808, apenas um ano após a Fenomenologia do espírito. A peça poética se abre com o sábio encarnando os ideais da Ilustração:

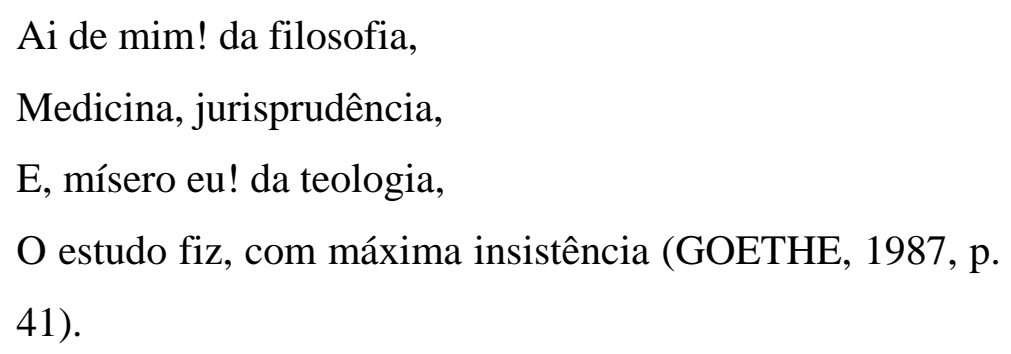

Mas Fausto, embora representando a ciência enciclopédica, capta os limites desse saber:
Pobre simplório, aqui estou
E sábio como dantes sou!
De doutor tenho o nome e mestre em artes,
E levo dez anos por estas partes, 
Pra cá e lá, aqui ou acolá

Os meus discípulos pelo nariz.

E vejo-o, não sabemos nada!

Deixa-me a mente amargurada (idem, ibidem).

Essa abertura da tragédia-poema em cinco atos, composta por Goethe, já anuncia o tema central da peça: a superação, pela descoberta da ação histórica, do saber formal desvinculado da prática, próprio da Ilustração.

Essa crítica do Iluminismo antecipa a problemática de fundo que irá contrapor as duas grandes concepções de filosofia da educação ao longo dos últimos cem anos: a concepção dialética, que será impulsionada especialmente pelo pensamento marxista, e a concepção pedagógica renovadora à qual se associam várias correntes, mas cuja expressão mais difundida é dada pelo pragmatismo, base principal do movimento escolanovista.

Ora, a referida problemática de fundo é exatamente a questão da ação. O marxismo irá levar às últimas conseqüências a crítica hegeliana libertando-a de sua carapaça mística (MARX, 1968, p. 17), isto é, despindo o método dialético de seu invólucro idealista, próprio do romantismo, de modo a desvendar o movimento objetivo da História enquanto produção da existência humana em seu conjunto.

Por sua vez, a filosofia da educação nova se desenvolve na atmosfera romântica de desconfiança na razão, comum a diferentes correntes que se constituíram entre o final do século XIX e a II Guerra Mundial, tais como o vitalismo (Bérgson), o historicismo (Dilthey), a fenomenologia, o existencialismo e o pragmatismo.

Enquanto o idealismo (Hegel) considera a atividade humana como essencialmente teórica, submetendo a prática à teoria, marxismo e pragmatismo se centram na prática. Entretanto, enquanto o pragmatismo (James e Dewey) concebe a atividade humana à luz da prática sensível, 
subordinando a teoria à prática, o marxismo busca compreender a atividade humana como unidade essencial entre teoria e prática, traduzida no conceito de práxis.

A primazia da prática decorre do próprio modo de constituição do ser humano. O homem é, com efeito, um ser natural que se destaca da natureza e entra em contradição com ela necessitando negá-la, enquanto natureza, para afirmar a sua humanidade.

$\mathrm{O}$ ato de destacar-se da natureza pode ser interpretado, do ponto de vista antropológico, como o momento em que o hominídeo assume a posição ereta. Apoiando-se sobre os pés, as mãos são liberadas para agir, para manipular a natureza que passa a ser vista como objeto (do latim "objectus”, lançado diante), como algo disposto diante de si e que pode ser usado como instrumento, como meio para satisfazer suas necessidades. Com a liberação das mãos e o conseqüente ato de manipulação, isto é, o trabalho sobre a natureza, emerge também a consciência, ou seja, a percepção do uso de certos meios para se chegar a determinado resultado. Diante dos objetos (ob-jecti), o homem define-se como projeto (pro-jectus, lançado adiante).

De fato, como assinalou Marx naquela famosa passagem de $O$ Capital, “o que distingue o pior arquiteto da melhor abelha é que ele figura na mente sua construção antes de transformá-la em realidade. No fim do processo do trabalho aparece um resultado que já existia antes idealmente na imaginação do trabalhador”. Essa antecipação mental configura o projeto. Aliás, o próprio Marx continua afirmando que o trabalhador "não transforma apenas o material sobre o qual opera; ele imprime ao material o projeto (grifo meu) que tinha conscientemente em mira, o qual constitui a lei determinante do seu modo de operar e ao qual tem de subordinar sua vontade” (MARX, 1968, p.202).

Ora, a emergência da consciência traduzida nessa capacidade de projetar, põe em evidência a questão da temporalidade que implica a diferença entre o antes e o depois, vale dizer, a relação entre passado, presente e futuro, isto é, a história. Assim, a existência humana, embora 
originária da natureza, resulta de uma ação que a nega manifestando-se como projeto dos próprios homens e, enquanto tal, configura-se como um fenômeno cultural que se desenvolve no tempo. Portanto, a existência humana se manifesta como temporalidade, isto é, como história. Segue-se, pois, que o homem é um ser essencialmente histórico, isto é, produto de seus próprios atos.

Diante do mencionado fenômeno, a necessidade do homem conhecer o mundo para agir sobre ele deu origem à atividade científica que veio a incidir não apenas sobre os objetos da ação, mas também sobre os próprios atos que consubstanciam a referida ação. Essa atividade de conhecimento metódico e sistemático das ações humanas é o que se convencionou denominar de "ciências da prática”. Entre elas se situam a ética, a política e a pedagogia. Esta última, conforme Schmied-Kowarzik, é “justamente uma das ciências práticas mais ricas em tradição” (SCHMIED-KOWARZIK, 1983, p.7).

Pela identidade comum de ciências da prática ética, política e pedagogia mantêm estreitas relações entre si, rebatendo-se umas nas outras, o que nos permite reconhecer a dimensão ética da política e da pedagogia, assim como a dimensão política da ética e da pedagogia e, igualmente, a dimensão pedagógica da ética e da política. Assim sendo, a investigação sobre ética e política se põe como uma exigência incontornável da pesquisa educacional e do desenvolvimento científico da pedagogia.

\section{A investigação sobre ética e política}

Na investigação sobre ética, como também sobre política, é desejável que o ponto de partida seja a articulação entre os aspectos histórico e lógico. Com efeito, dado o caráter histórico das manifestações humanas, as doutrinas ou concepções éticas e políticas surgem e se transformam conforme variam as épocas e os tipos de sociedade. Esta se modifica em função das respostas exigidas pelas relações que os homens travam entre si, 
especificamente no que se refere aos comportamentos morais, no caso da ética, e às organizações das formas de governo, no caso da política.

Ética e política devem, pois, ser consideradas, por um lado, tendo em vista a história humana de modo geral e a história das sociedades às quais se referem; e, por outro lado, levando em conta a história interna em que se tece sua lógica própria, uma vez que cada concepção ética ou política se conecta com as anteriores e com as posteriores, num processo de continuidade e ruptura.

Estabelecido esse parâmetro metodológico preliminar, o segundo passo envolverá a identificação das temáticas básicas que consubstanciam os campos epistemológicos da ética e da política. Ou seja, trata-se, agora, de captar o nexo lógico que resultou do desenvolvimento histórico dessas disciplinas.

Nesse âmbito constatamos que o campo da ética se constituiu pela depuração da experiência moral no interior da vida social. Conseqüentemente, se na linguagem comum as palavras "ética” e "moral" são usadas como sinônimos, significando os princípios e normas da boa conduta ou a própria conduta quando guiada por regras que conduzem a praticar o bem e evitar o mal, em sentido técnico a "ética” se refere aos princípios e normas enquanto tais e, mais especificamente, à ciência ou à parte da filosofia que estuda esses princípios e normas buscando distinguir entre o bem e o mal. Em contrapartida, a "moral” corresponde à retidão dos costumes que conduzem a ações consideradas corretas e meritórias no seio de uma determinada comunidade que compartilha um mesmo sistema de valores.

Como assinala Sánchez Vázquez, as questões éticas se caracterizam pela sua generalidade distinguindo-se da moral da vida cotidiana que é o campo dos problemas dos juízos morais que enfrentamos em situações concretas. Daí a definição que propõe: “A ética é a teoria ou ciência do comportamento moral dos homens em sociedade” (SÁNCHEZ VÁZQUES, 1970, p.12). Nessa condição, o objeto da ética são “os atos conscientes e 
voluntários dos indivíduos que afetam outros indivíduos, determinados grupos sociais ou a sociedade em seu conjunto” (IBIDEM, p.14). Dessa maneira, a ética e a moral, seja pelo étimo grego ( ethos), seja pelo latino (mos), estão ligadas a um modo de ser, caráter, costumes, hábitos não inatos mas adquiridos ou conquistados pelos homens na medida em que, no processo de produção de sua existência, eles travam relações entre si as quais os afetam reciprocamente.

A política, na Antigüidade grega, abarcava toda a esfera da vida social, conforme o sentido etimológico ligado à organização da cidade. Com o advento do cristianismo que estabeleceu a separação entre poder espiritual e poder temporal, o poder espiritual foi subtraído à esfera política ficando no âmbito da religião. E com a configuração da sociedade burguesa baseada na liberdade de mercado, também o poder econômico é apartado da política, cujo âmbito se confina ao poder público. Estabelece-se, então, a distinção entre os conceitos de sociedade civil, referente às relações privadas, e sociedade política relativa à esfera pública. Assim, a ciência política, cujo objeto eram as relações de poder no conjunto da sociedade, concentrou seu foco no estudo das relações de poder que têm como epicentro o Estado.

Enquanto ciência dos comportamentos morais, as concepções de ética se desenvolveram na história conforme duas orientações distintas. A primeira entende que o objeto da ética consiste na determinação da finalidade que deve guiar a conduta humana e na identificação dos meios que conduzem àquela finalidade. Já a segunda orientação se fixa nas forças ou nos motivos que movem a conduta humana em determinada direção.

No primeiro caso temos uma orientação de matiz ontológico: o ideal a atingir, a finalidade expressa pela palavra "bem” corresponde a uma idéia universal ou à própria natureza humana da qual são deduzidas as normas de conduta. Trata-se de uma ética dos fins, fundada na razão.

No segundo caso tem-se um viés, por assim dizer, de ordem psicológica: o "bem” a atingir decorre do desejo de prazer, que impulsiona 
as ações humanas. Aqui estamos diante de uma ética da motivação, fundada nos sentimentos.

Por sua vez, o poder político, cujo substrato é a desigualdade social, se impôs historicamente como o poder supremo por deter o monopólio do uso legítimo da força. A ele se subordinam todos os demais poderes e a ele recorrem os grupos dominantes que o constituem como a razão última para a defesa de seus interesses tanto contra eventuais ataques externos como contra pressões internas.

Nessas circunstâncias estabelece-se uma contraposição entre moral individual e moral coletiva, tipificada no enunciado da "razão de Estado", assim explicitada por Norberto Bobbio:

Por "razão de Estado" se entende aquele conjunto de princípios e máximas segundo os quais ações que não seriam justificadas, se praticadas só pelo indivíduo, são não só justificadas como também por vezes exaltadas e glorificadas se praticadas pelo príncipe ou por quem quer que exerça o poder em nome do Estado [...] A afirmação de que a Política é a razão do Estado encontra perfeita correspondência na afirmação de que a moral é a razão do indivíduo" (BOBBIO, 1999, p. 962).

O terceiro passo da investigação conduziria a um inventário das principais teorias éticas e políticas, uma espécie de estado da arte, que teria que começar necessariamente pela contribuição grega (sofistas, Sócrates, Platão, Aristóteles, estoicismo e epicurismo); passaria pelos enfoques teológico e filosófico do período medieval e pelas rupturas da época moderna quando a razão e a filosofia se desligam da fé e da teologia, as ciências naturais se libertam dos pressupostos teológicos, o Estado se separa da Igreja e o homem se desvincula de Deus; e chegaria ao momento contemporâneo com a contraposição entre o idealismo transcendental e o existencialismo e entre o pragmatismo desdobrado no neutralismo da filosofia analítica e o marxismo com o seu conseqüente compromisso éticopolítico.

O outro passo da investigação sobre ética e política envolve o problema da identificação, classificação e seleção das fontes, distinguindo 
entre os textos clássicos e os documentos específicos que contêm as informações necessárias à análise das questões delimitadas para estudo. Nesse particular cabe lembrar que, de modo especial em relação às fontes clássicas, um mesmo texto pode figurar nos diferentes ramos em que incide a investigação, o que pode ser ilustrado pelo livro “A república” de Platão que se apresenta como fonte direta tanto da ética como da política e da pedagogia.

Indicado o ponto de partida teórico-metodológico; sinalizada a direção em que se movem os conteúdos da ética e da política; inventariadas as principais teorias éticas e políticas; e identificado o material empírico consubstanciado nas fontes a serem analisadas, estariam postas as condições preliminares para se formular projetos específicos de pesquisa nos campos da ética e da política. Tais projetos terão o propósito de explorar as questões éticas e políticas que repercutem na educação enquanto atividade que se inscreve na esfera pública sujeita, portanto, ao poder de Estado, com a incumbência de formar indivíduos moralmente aptos para agir no ambiente societário.

\section{Conclusão: importância para a formação do educador}

A importância de uma linha de investigações sobre ética e política na formação do educador decorre da própria natureza da educação entendida como o "ato de produzir, direta e intencionalmente, em cada indivíduo singular, a humanidade que é produzida histórica e coletivamente pelo conjunto dos homens” (SAVIANI, 2008, p. 13). Nessa condição, a educação assume o caráter de uma atividade mediadora no seio da prática social inserindo-se, portanto, no coração da ética e da política, já que lhe cabe atuar sobre os indivíduos visando, porém, sua inserção social, o que implica a constante articulação entre a "razão moral” e a "razão de Estado".

Além desse caráter intrínseco, a investigação sobre ética e política resulta importante para que possamos enfrentar os desafios morais, éticos e políticos que sobrevêm ao processo de formação dos profissionais da 
educação, sejam eles os pedagogos ou os professores das diferentes disciplinas escolares, assim como os agentes das diversas atividades que compõem o complexo da educação extra-escolar.

Os desafios morais se expressam nos problemas da vida cotidiana que, como educadores, enfrentamos constantemente nas escolas, em sala de aula, nas relações com os alunos, com os professores, com os pais e na sociedade de modo geral.

Por sua vez, os desafios éticos, incidindo sobre os atos conscientes e voluntários dos indivíduos que afetam a sociedade em seu conjunto, nos obrigam a deslindar os próprios fundamentos da vida em sociedade.

Os desafios morais e éticos se manifestam de forma particularizada nas condições que vigoram hoje em nossa sociedade.

Não se pode dizer que a sociedade atual carece de ética. De fato, ela tem uma ética que lhe é própria e que está referida a alguns princípios gerais e abstratos que subsumem, entretanto, valores concretos que consubstanciam a forma de vida própria da sociedade burguesa. Assim, os princípios da liberdade, igualdade, democracia e solidariedade humana são subsumidos pelos valores do individualismo, da competição, da busca do lucro e acumulação de bens os quais configuram a moral burguesa que tem sua justificação teórica numa ética também burguesa, erigindo-se, sobre esses mesmos valores, a política burguesa. E a educação é chamada, na sociedade burguesa, a realizar a mediação entre ética e política, formando os indivíduos de acordo com os valores requeridos por esse tipo de sociedade. Assim, pela mediação da educação, se buscará instituir, em cada indivíduo singular, o cidadão ético correspondente ao lugar a ele atribuído na escala social. Nesse contexto, as investigações sobre ética e política nos permitirão enfrentar com maior clarividência os desafios que a situação de violência, corrupção, estímulo ao hedonismo, à competição, ao espírito de "levar vantagem em tudo” está colocando para a educação na sociedade brasileira atual.

Por fim, a investigação sobre política nos ajudará a enfrentar os desafios representados pelos limites que a organização do Estado e dos 
governos impõe à formação de educadores, limites esses que se objetivizam, de forma explícita ou camuflada, nas medidas de política educacional formuladas e implementadas pelas diferentes instâncias governamentais.

Tendo apresentado, à guisa de abertura desse simpósio, algumas indicações básicas sobre o tema relativo à investigação sobre ética e política no âmbito da educação, espero ter contribuído para o desenvolvimento das demais atividades que irão aprofundar e detalhar os vários aspectos do tema que não puderam ser contemplados nesta breve exposição inicial. Bom trabalho a todos!

\section{Referências}

BOBBIO, Norberto (1999). "Verbete Política". In: BOBBIO, Norberto; MATTEUCCI, Nicola; PAQUINO, Gianfranc. (1999). Dicionário de política, $12^{\mathrm{a}}$ ed. Brasília, Editora UnB, vol.2, p. 954-962.

CANO, Rubén López (2000). Música y Retórica en el Barroco. México: Universidad Nacional Autonoma de México.

CERVANTES, Miguel de (2004). Don Quijote de la Mancha. Real Academia Española, Santillana Ediciones Generales, S.L. (Edición del IV Centenario).

GOETHE, Johann Wolgang von (1987). Fausto. Belo Horizonte, Itatiaia.

HANSEN, João Adolfo (2000). "A civilização pela palavra". In: LOPES, E.M.T., FARIA FILHO, L.M. e VEIGA, C.G. [Orgs.], 500 anos de educação no Brasil, $2^{a}$ ed. Belo Horizonte, Autêntica, p.19-41.

HEGEL, Georg Wilhelm Friedrich (1973). Fenomenologia del espiritu. México, Fondo de Cultura Económica.

MARX, Karl (1968). O capital. Rio de Janeiro, Civilização Brasileira.

SAVIANI, Dermeval (2008). Pedagogia histórico-crítica: primeiras aproximações, $10^{\mathrm{a}}$ ed. Campinas, Autores Associados.

SÁNCHEZ VÁZQUEZ, Adolfo (1970). Ética. Rio de Janeiro, Civilização Brasileira.

SCHMIED-KOWARZIK, Wolfdietrich (1983), Pedagogia dialética: de Aristóteles a Paulo Freire. São Paulo, Brasiliense. 